\title{
Reform of Hydraulic Transmission Course in the Background of the Excellent Engineer Education Plan
}

\author{
Jiang Jihai, Li Huanhuan \\ Department of Fluid Control and Automation \\ School of Mechatronics Engineering \\ Harbin Institute of Technology \\ Harbin, China
}

\author{
Li Xiaowen \\ School of Foreign Languages \\ Harbin Institute of Technology \\ Harbin, China
}

\begin{abstract}
This paper is mainly about the reform of hydraulic transmission course. First, the requests and the meanings of the Plan of Excellent Engineer Education are discussed. Then, in this background, the reform issues of hydraulic transmission course are discussed. The main problems of traditional hydraulic transmission course are listed and analyzed: the contents of the textbooks were out-of-date; the experiments were not fit for the new technology; there were too many theory classes; the students had little chance to practice and the teachers had no practical experiences. To solve these problems and to fit the requirements of The Plan of Excellent Engineer Education, more attention should be paid to how to combine the production, teaching, research and applying system, to training innovative talents through the reform of hydraulic transmission courses.
\end{abstract}

Keywords-hydraulic transmission course; plan of excellent engineer education; reform

\section{INTRODUCTION}

The higher engineering education of our country has made great achievements to be the first in the world through several decades of development. The system of higher engineering education is reasonable. Engineering education has trained tens of millions of engineering science and technology talents. Engineering education has stood for the formation and development of industrial system and 30 years of rapid economic growth since China's reform and opening up, which has made greater contributions to our country's socialist modernization.

Since the Party's 17th National Congress, our party central committee and State Council have made a series of important deployment to build an innovation-oriented country, construction of reinvigorating China through human resource development, which puts forward the urgent request for the reform and development of higher engineering education and for adhering to a road to brand-new industrialization within China to cultivate a large number of engineering talents who can adapt to and support the industrial development. Thus, it is urgent for innovation-oriented country construction and the engineering team's innovation capability improvement in science and technology by cultivating a large number of innovative engineering talents. What's more, it is urgent for the comprehensive national strength and the challenges of economic globalization to cultivate a large number of engineering talents with international competitiveness. Our Ministry of Education proposed "an outstanding engineers training plan" in education. And the kick-off meeting was held in Tianjin on June 23, 2010, which called for the cooperation between schools and industries to carry out "the outstanding engineers training plan." The main target is geared at meeting the needs of the industry, the world and the future, training a large number of engineers with strong innovation ability so as to meeting the needs of the economic and social developments and to have a solid human resource advantages for an innovative country, industrialization and modernization and to enhance the core competitiveness and overall national strength of our country. The "excellence initiative" has the following three characteristics. Firstly, industrial enterprises get deeply involved in cultivation. Secondly, the school trains engineering talents according to the general standard and industrial standards. The most important characteristic of the "excellence initiative" is that it enriches students' engineering ability and innovation ability. The "excellence initiative" acts based on the principles of the "industrial guidance, cooperation between colleges, classified implementations and various forms

\section{THE FUNDAMENTAL CONTENTS OF THE PLAN OF EXCELLENT ENGINEER EDUCATION}

The Plan of Excellent Engineer Education is an important measure to promote the reform and the quality of higher engineering education in our country .The basic contents of the plan include six points. Firstly, it is the guiding ideology, by which we emphasize the engineering education concept about "for the industry, for the future, and for the world" and focus on improving the engineering consciousness, engineering quality and the ability of engineering practice for creating the mode of engineering education with Chinese characteristics and with the social demands as the guide, with the actual project as the background, and with engineering technology as the main line, and make overall plans for the training goal which students should achieve in the campus and enterprise studies by the close cooperation between schools and enterprises. Secondly, it is the cultivation objectives that cultivate various types of engineering and technical personnel with strong capacity for innovation and the ability to meet the needs of enterprise development. Thirdly, it is industrial participation that mainly includes the traditional industries and the new strategic industries. Fourthly, it is the fostering standard with three levels that contains the basic standards, industrial standards and the fostering standard of schools. Fifthly, it is the cultivation mode that students are cultivated by 
the joint cooperation of enterprises and Universities. The cultural process contains two parts: the school study and the enterprise study. Lastly, it is the teaching staff. The teachers who participate in the Plan of Excellent Engineer Education should own the engineering experience of working in enterprises or horizontal scientific research.

\section{THE DEMAND OF EXCELLENT PLAN FOR THE HYDRAULIC TRANSMISSION COURSE}

Under the background of the excellent engineering plan, the basic components, the goal and the implementing principles of the excellent plan, new demands are put forward to improve the traditional hydraulic transmission course. The hydraulic transmission technique plays an important role in our national economy. The hydraulic transmission technique makes use of fluid pressure to deliver power, which is one of the key technologies to develop the mechanical and electrical products in ways of a high speed, automatic and high efficiency, high precision, high reliability, lightweight, and diversification. According to some statistics, 95 percent of engineering machines, 90 percent of CNC machining centers, and 95 percent of the automatic production lines made in and aboard all adopt the hydraulic transmission technology, and the level of the hydraulic transmission technology has been the sign of national industrial development. Hydraulic transmission technology is a very important professional basic course for most of the professions of engineering. Traditional lectures that only focused on hydraulic transmission could not fit the goal of cultivating the excellent engineers. Under the new situation, schools need to make some enforceable teaching strategy of course, to organize the teaching materials and contents according to the goal of the plan of "Educating and Training Excellent Engineers", to do some research on the innovative teaching methods and means, to consider the cultivation and progress of teachers to fit the demand of the excellent plan, and to adjust the evaluation modes of course with the changing of the teaching methods and contents. Therefore, we firstly need to be clear about the current situation and existing problems of the hydraulic transmission course.

\section{THE CURRENT SITUATION AND THE EXISTING PROBLEMS OF THE HYDRAULIC TRANSMISSION COURSE}

The current situation and main problems of the past hydraulic transmission course are as follows:

(1) The past teaching methods and contents of hydraulic transmission course are old-fashioned and many schools have not made any changes in them for a long time, therefore, they could not keep up with the pace of times and technological development and could not adapt to the changing characteristics of students.

(2) The laboratories and training rooms that facilitate the courses could not fit the industry and the equipment and experimental methodology were old-fashioned so that they could not be prepared for the newest technological level.

(3) The past hydraulic transmission courses were conducted only within the classrooms in isolation from production environment and reality; in that situation, students had no idea about what they were learning or the application of the knowledge; students felt bored and had no learning enthusiasm.

(4) Since the teachers, who are graduated from schools directly, had no experience of working in the factory, they were ill-equipped with the professional quality and subsequently the ability of teachers greatly influenced the teaching efficiency.

(5) The lessons, which are given priority to the theory, ignore the cultivation of students' initiatives and tackle some difficult structures and theories only by means of the charts and models. These teaching methods and means make students not only hardly understand knowledge but also have no interest in learning this course.

(6) The disconnection between theory teaching and practice is very serious in the past. All the theories and even the formulas were taught to students in the classroom, and students could analyze the theory of hydraulic circuit merely in isolation, but they had no ideas about the specific operations on the connection of hydraulic valve opening and the regulation of overflow valve, and some students even could not figure out the hydraulic pump, which could not help to achieve the goal of cultivating talents. Solutions are the following:

Firstly, we should pay more attention to cultivating students' abilities of engineering practice, adjust and optimize the teaching plan and practical contents of course, combine practical contents with specific industrial sectors which contain rail transit, petroleum chemical equipment, port equipment, agricultural machinery, engineering machinery, and so on, and conduct integrated optimization design of the practical content. We should cultivate students' ability of thinking, improve their perceptual knowledge and operational ability, exercise students' ability to analyze and solve problems consciously by guiding students to the process of analyzing experimental data and improving the training of students' comprehensive ability. The training projects should be developed with the examples in production. And students' innovative ability, practical ability, team spirit, and responsibility should be cultivated with the practical item. Training contents should contain circuit design, component selection, assembling circuit and circuit debugging, troubleshooting, finishing equipment, group discussion and training record, and so on.

Secondly, the comprehensive and innovative hydraulic drive laboratory should be built. While hydraulic transmission technology pays more attention to exerting students' initiative and creativity, we should introduce teaching into the enterprise to realize the combination of engineering and three approaches which contain production, technology, and process. We should make the teaching more targeted and more practical, and students can have a visualized learning so that they can master knowledge efficiently and get into character after working. So, the setting of the comprehensive and innovative hydraulic transmission laboratory can meet not only students' practical need but also the university-enterprise united public equipment to enhance the operational ability and the ability of analyzing 
and solving practical problem and cultivate the innovative spirit.

Thirdly, a close university-enterprise cooperation relationship should be built and the hydraulic transmission course should be combined with backbone enterprises, mechanical and electrical equipment of hydraulic transmission industries and the university-industry cooperation should be realized. The close cooperation with enterprises is as follows: setting up the base for practice where students can visit and realize actual exercise as part of the hydraulic transmission teaching course, establishing teachers' training system among teachers, engineers and senior technicians to give enterprises technique services and carry out scientific research and public relations with technique project and practical teaching through university-enterprise cooperation, international cooperation and educational communication at home and abroad, developing staff training that can cultivate and exercise the teachers of hydraulic transmission course.

Then, the teaching staff should be constructed in accordance with the excellence plan by which courses are conducted by professors or associate professors who are equipped with corresponding auxiliary staff to do experimental preparation and experimental guidance and are of knowledge, teaching ability and experience of working in the hydraulic transmission industry. Thus, the key of fostering excellent engineers is to increase the teachers' training and professional support and cultivate excellent teachers.

Lastly, the hydraulic transmission teaching materials should be selected applicable to excellent cultivation plan, and modern teaching means and teaching methods should be adopted so as to show students the hydraulic transmission in accordance with the characteristics of the students in all directions and to increase the students' interest in learning so as to achieve good effect and cultivate students' comprehensive ability by combining with practical situation where electrical, mechanical and control courses may be involved.

\section{CONCLUSION}

The reform of the hydraulic transmission course that focuses on the setting of overall plan for the course follows the repetitive process from perceptual knowledge to rational knowledge ,from practice to theory, from theory to practice and synthetically consider to make use of the advantage of industry-university-research institution to cultivate hydraulic transmission technology innovative talents in the course of teaching by drawing lessons from foreign experience in course planning and combining the overall consideration and layout of the teaching process of Marxism epistemology according to the different projects applied to different tests.

To the specific major, the status and effect of the hydraulic transmission technology should be analyzed from the overall professional perspective and a targeted tailor-made course plan should be formulated respectively and the optimized materials on the hydraulic transmission excellent engineers training should be compiled by combining with the requirement of "excellent plan" and continual conclusion in the teaching.
Under the mode of industry-university research institution which contains perceptual knowledge in practice, school theory learning in the classroom, research and exploration of the professional question and the study from employers, students apply the theory knowledge to the associated practical work that is working for employers and getting paid and bring the challenges and growth encountered in the work back to the classroom to help students to have a further analysis and thinking in the study and realize the industry-universityresearch to promote the study of hydraulic transmission course. Teachers should continually enhance the theoretical knowledge and teaching skills, increase the practice experience, and broaden the horizons by combining the characters of the Excellent Plan and hydraulic transmission course consciously and actively.

When the reform of hydraulic transmission course is carried out, we can select a class to have the pilot study and formulate the specific hydraulic transmission teaching scheme, test new teaching means and methods, apply new teaching materials, aiming at cultivating the characters of students in different classes and majors and summarize, and perfect it gradually to further push forward the reform of hydraulic transmission course eventually under the background of Excellent plan

\section{ACKNOWLEDGMENT}

This paper is supported by the project of Teaching Reform of Higher Education in Heilongjiang Province.

\section{REFERENCES}

[1] Pei-wei song. The ideas and ways to cultivate innovative ability of excellent engineers [J]. China power education, 2011, (7) 25 to 29

[2] De-cai li,Jun wang .Several views about cultivating "excellent engineer" $[\mathrm{J}]$. Journal of graduate student education research, 2011, (6) 53-57

[3] Jun du, Dan zhao, Yang kang. Research on the practical teaching reform of hydraulic transmission under the mode of engineering integration[J]. Mechanical management and development, 2010, (6) 142-145

[4] Shu-zi Yang,Furun Zhang. The root of innovation is in practice [J]. Journal of higher engineering education research, 2001, (2) 9-12

[5] Fang-ping huang, Meng-hong shen, Sen-lin tong. The exploration of practical system construction on cultivating the hydraulic transmission characteristic talent [J]. Journal of suzhou university (engineering), 2008, (8) $79-80$

[6] Jian-qiang liu. The influence of applied science university in Germany on the "outstanding engineers training plan" [J]. Journal of higher education research, 2010, (6) 50 to 52

[7] Jian lin.The cultivation of excellent engineers by the cooperation between colleges and enterprises. [J]. Journal of higher engineering education research, 2012, (3) 7 to 23

[8] Jian lin.The reform of curriculum system and teaching content on "outstanding engineers training" $[\mathrm{J}]$. Journal of higher engineering education research, 2011, (5) 1-5

[9] Jian lin.The construction of teaching team on the qualified and excellent engineer training $[\mathrm{J}]$. Journal of higher engineering education research, 2012, (1) 1-14

[10] Ke-zhen han, jun-ying liu, Yong wang, etc. The discussion on hydraulic experimental teaching reform under the goal of excellent engineer training [J]. Journal of higher education research, 2013, (2) 86 